\title{
Pressure-controlled migration of paramagnetic centers in a heterospin crystal
}

Victor Ovcharenko, ${ }^{* a}$ Galina Romanenko, ${ }^{a}$ Alexey Polushkin, ${ }^{a}$ Gleb Letyagin, ${ }^{\mathrm{a}, \mathrm{g}}$

Artem Bogomyakov, ${ }^{a}$ Matvey Fedin, ${ }^{a}$ Kseniya Maryunina, ${ }^{b}$ Sadafumi Nishihara, ${ }^{b, c}$ Katsuya Inoue,${ }^{b, c}$

Marina Petrova, ${ }^{a}$ Vitaly Morozov, ${ }^{\mathrm{a}, \mathrm{g}}$ and Ekaterina Zueva ${ }^{\mathrm{d}, \mathrm{e}, \mathrm{f}}$

${ }^{a}$ International Tomography Center SB RAS, 3A Institutskaya Str., Novosibirsk 630090, Russia

${ }^{b}$ Department of Chemistry, Graduate School of Science and Chirality Research Center (CResCent), Hiroshima University, 1-3-1, Kagamiyama, Higashi Hiroshima, Hiroshima, 739-8526, Japan

${ }^{c}$ Institute for Advanced Materials Research, Hiroshima University, 1-3-1 Kagamiyama, Higashi Hiroshima, 739-8526, Japan

${ }^{\mathrm{d}}$ Department of Inorganic Chemistry, Kazan National Research Technological University, $68 \mathrm{~K}$. Marx Str., 420015 Kazan, Russia

${ }^{\mathrm{e}}$ A. E. Arbuzov Institute of Organic and Physical Chemistry, Kazan Scientific Centre of the Russian Academy of Sciences, Arbuzov Str. 8,420088 Kazan, Russian

${ }^{\mathrm{f}}$ Kazan Federal University, Kremlyovskaya Str. 18, 420008 Kazan, Russia

${ }^{\mathrm{g}}$ Novosibirsk State University, Pirogova Str. 1, 630090 Novosibirsk, Russia

\section{Content}

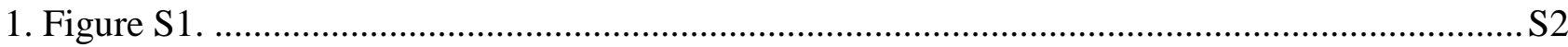

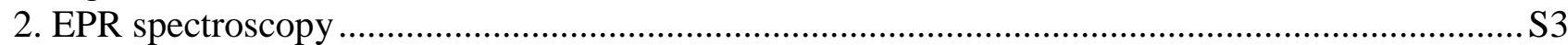

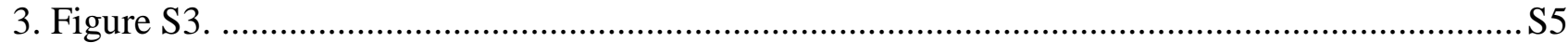

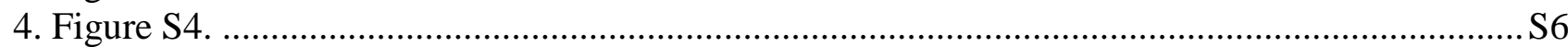

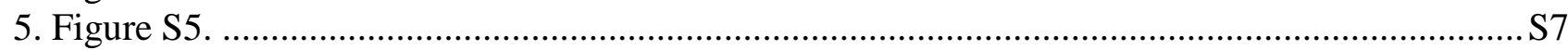

6. Table S1 .

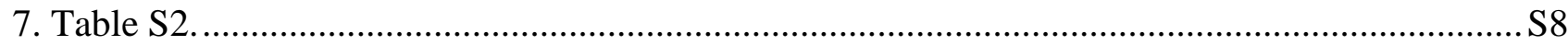

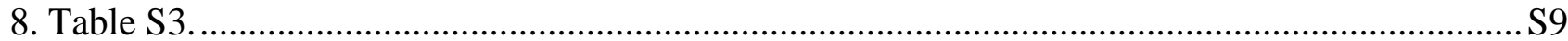

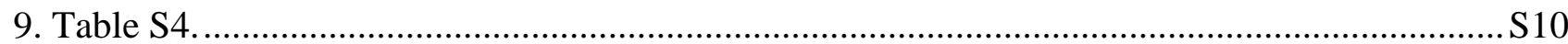

10. Interpretation of the anomalous behavior of $\chi \mathrm{T}(\mathrm{T})$ at low pressures ..................................... $\mathrm{S} 11$

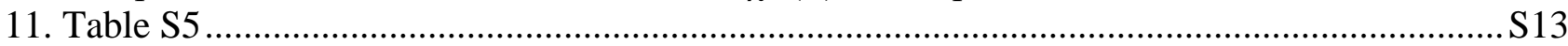




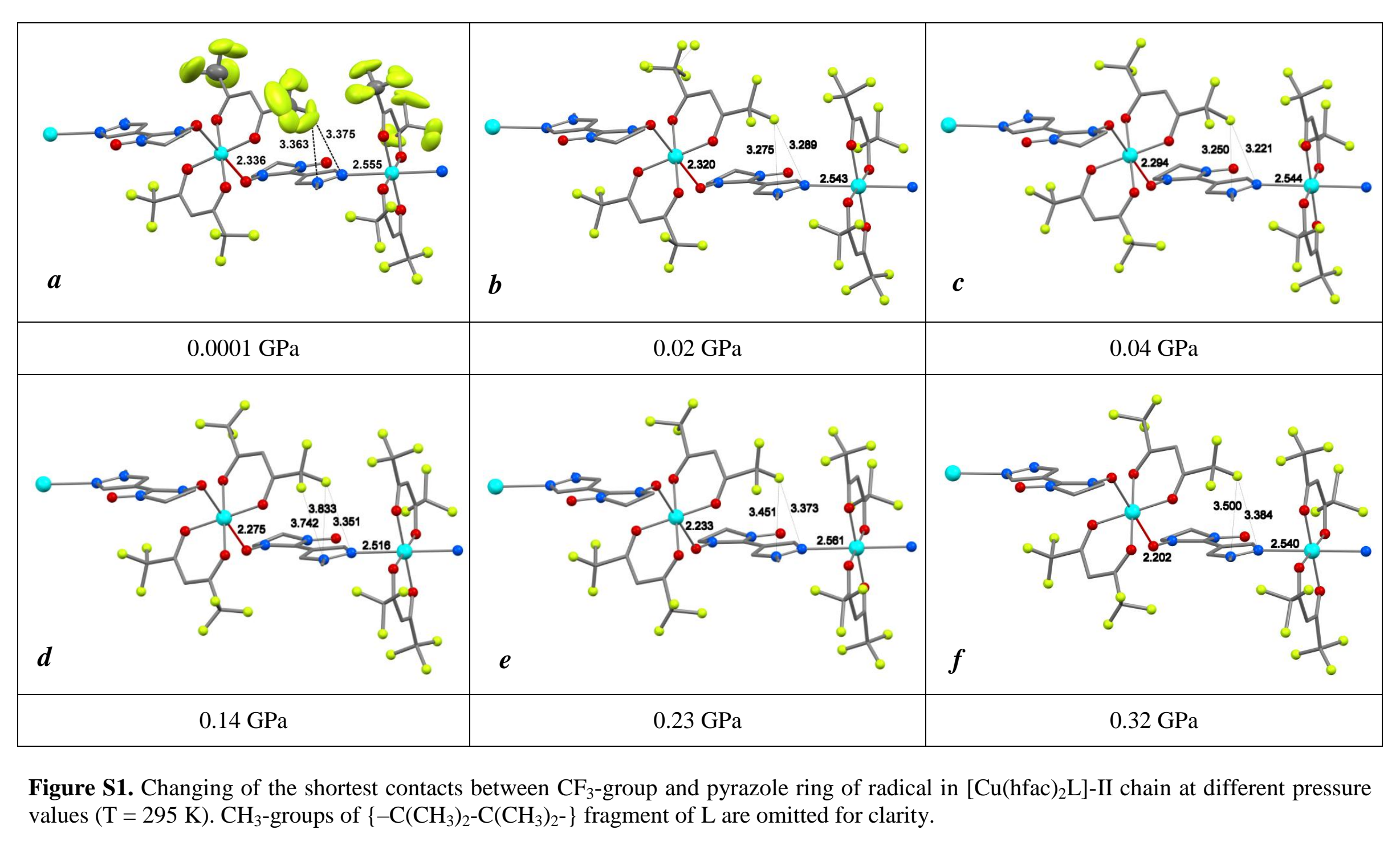




\section{EPR spectroscopy}
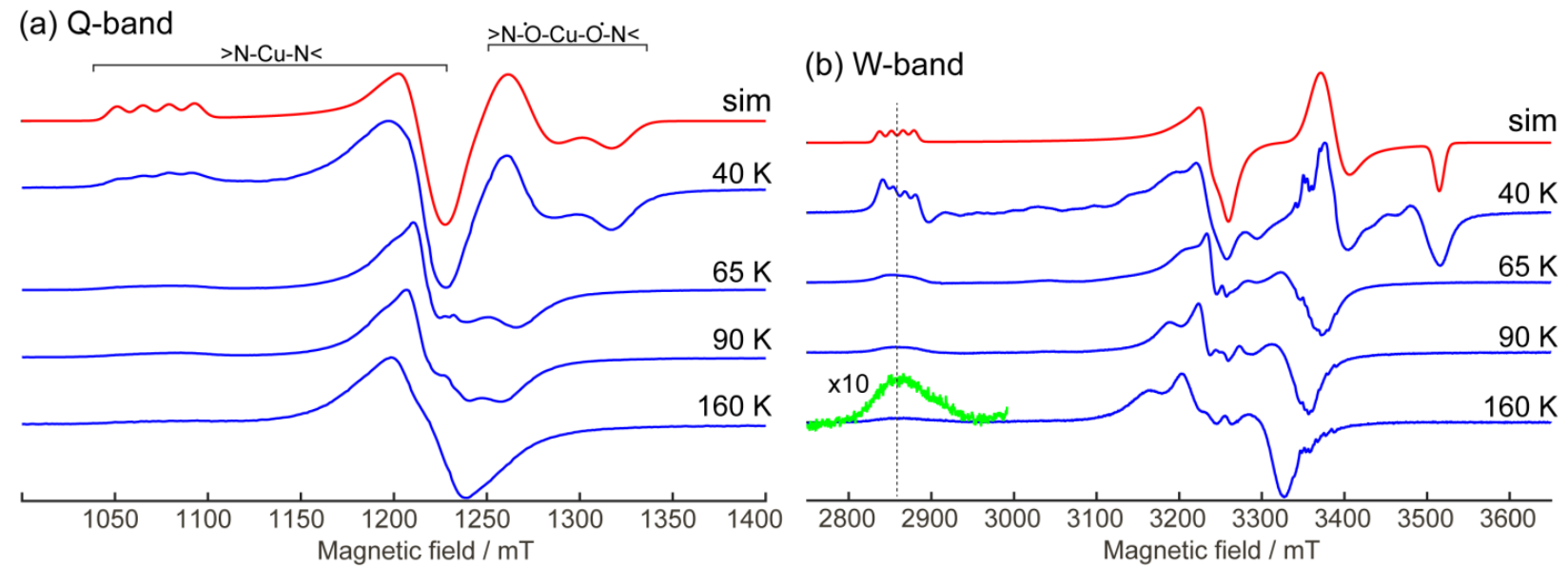

Figure S2. Variable-temperature CW EPR spectra of $\left[\mathrm{Cu}(\mathrm{hfac})_{2} \mathrm{~L}\right]-\mathrm{II}$ obtained at Q-band (a) and at $\mathrm{W}$-band (b). The temperatures are indicated on the right. Spectral regions corresponding to one-spin $>\mathrm{N}-\mathrm{Cu}-\mathrm{N}<$ unit and spin triad $>\mathrm{N}-{ }^{\circ} \mathrm{O}-\mathrm{Cu}-\mathrm{O}^{\circ}-\mathrm{N}<$ are schematically shown on top of the panel (a). Vertical dashed line in (b) guides the eye for position of $\mathrm{g}_{\|}$component of $>\mathrm{N}-\mathrm{Cu}-\mathrm{N}<$ unit. Red lines show simulations ("sim") obtained using the following set of parameters. Spin triad: effective $\mathrm{g}_{\perp}=$ 1.9930, $\mathrm{g}_{\|}=1.9165$. One-spin $\mathrm{Cu}$ (II) ion: $\mathrm{g}_{\mathrm{x}}=2.055-2.065, \mathrm{~g}_{\mathrm{y}}=2.082, \mathrm{~g}_{\mathrm{z}}=2.356$, hyperfine coupling tensor $\mathrm{A}\left({ }^{63} \mathrm{Cu}\right)=\left[\begin{array}{lll}3.5 & 3.5 & 16.5\end{array}\right] \mathrm{mT}$.

Figure S2 shows the variable-temperature continuous wave EPR spectra for compound $\left[\mathrm{Cu}(\mathrm{hfac})_{2} \mathrm{~L}\right]-\mathrm{II}$ obtained at Q- and W-bands $(34 / 94 \mathrm{GHz})$. Each of three steps in the $\mu_{\mathrm{eff}}(T)$ dependence leads to a noticeable change of the EPR spectrum, but the most striking difference is observed below the lowest-temperature jump $(\approx 56 \mathrm{~K})$. At $T=40 \mathrm{~K}$ the spectrum of spin triad located at $\mathrm{g}<2$ region becomes well resolved from the spectrum of one-spin copper(II) in $>\mathrm{N}-\mathrm{Cu}-$ $\mathrm{N}<$ coordination units. As was shown in a series of previous works ${ }^{1}$, this unambiguously means that Jahn-Teller axis in $\mathrm{CuO}_{6}$ units $\left(>\mathrm{N}-{ }^{\bullet} \mathrm{O}-\mathrm{Cu}-\mathrm{O}^{\bullet}-\mathrm{N}<\right)$ has flipped and ${ }^{\bullet} \mathrm{O}-\mathrm{Cu}-\mathrm{O}^{\bullet}$ distances have shortened, leading to a strong antiferromagnetic exchange interaction between copper(II) and nitroxide spins $(|J|>>k T)$. In such conditions spin triad has an effective spin $S=1 / 2$.

In general, EPR behavior of $\mathrm{Cu}(\mathrm{hfac})_{2} \mathrm{~L}^{\mathrm{Me}}$ upon spin transition at $56 \mathrm{~K}$ is characteristic for the conversion of spin triads from weakly-coupled to a strongly-coupled spin state (WS/SS states),

1. M. V. Fedin, S. L. Veber, E. G. Bagryanskaya, V. I. Ovcharenko. Electron paramagnetic resonance of switchable copper-nitroxide-based molecular magnets: An indispensable tool for intriguing systems. Coord. Chem. Rev., 2015, 289-290, 341-356. 
that was observed in many other breathing crystals. ${ }^{1}$ However, interpretation of spectral changes during two higher-temperature transitions (around 75 and $140 \mathrm{~K}$ ) is less clear. We notice, especially at W-band (Figure S2b), that upon each transition the EPR line of spin triad moves, having progressively higher field position in each case $(160 \mathrm{~K} \rightarrow 90 \mathrm{~K}, 90 \mathrm{~K} \rightarrow 65 \mathrm{~K})$. But, at both 90 and $65 \mathrm{~K}$, the spectrum of spin triad shows unresolved g-anisotropy, i.e. it is represented by a single broad line. We have shown previously that, in addition to exchange interactions copper(II)nitroxide, strong intercluster exchange operates between spin triads in the crystal. ${ }^{2}$ This intercluster coupling leads to efficient exchange-narrowing, therefore, if a fraction of spin triads resides in WS state and another fraction in SS state, the spectrum with average parameters will be observed. We believe that this is the reason for observation of single EPR line of spin triad with unresolved ganisotropy, which moves stepwise upon each spin transition. A fraction of spin triads convert from WS to SS state below $\sim 140 \mathrm{~K}$, and another fraction converts to SS state below $\sim 75 \mathrm{~K}$, whereas the complete conversion of all triads to SS state occurs only below $\sim 56 \mathrm{~K}$. At $T<56 \mathrm{~K}$ we observe most typical " $\mathrm{g}<2$ signals" of spin triads with anisotropic g-tensor $\mathrm{g}_{\perp}=1.9930, \mathrm{~g}_{\|}=1.9165$.

The observations for the one-spin $\mathrm{Cu}(\mathrm{II})$ ion in $\mathrm{CuO}_{4} \mathrm{~N}_{2}(>\mathrm{N}-\mathrm{Cu}-\mathrm{N}<)$ units are also characteristic of strong intercluster interactions. We established previously that in most breathing crystals intercluster interactions propagate across the structural polymeric chains via short contacts between NO-groups of nitroxides, i.e. between spin triads [2]. In such case, copper(II) ions in $\mathrm{CuO}_{4} \mathrm{~N}_{2}$ units are virtually magnetically isolated, leading to observation of well-resolved hyperfine splitting on $\mathrm{g}_{\|}$component of copper due to its nuclear spin $I=3 / 2$ (lowest-field feature). However, in some cases intercluster exchange was found to propagate along the polymeric chain, leading to the averaging of individual signals of one-spin $\mathrm{Cu}$ (II) ion and spin triads [1]. In such case, no hyperfine splitting could be observed on $\mathrm{g}_{\|}$component of copper. In case of $\mathrm{Cu}(\mathrm{hfac})_{2} \mathrm{~L}^{\mathrm{Me}}$, we observe the resolved hyperfine splitting only below $56 \mathrm{~K}$. This means that structural rearrangements in spin triads also affect the pathways of intercluster exchange. At 160, 90 and $65 \mathrm{~K}$ the intercluster exchange is essential both along and across the polymeric chain (i.e. between one-spin units and spin triads of the same polymer chain, and between spin triads of neighboring polymer chains, correspondingly). At the same time, at $40 \mathrm{~K}$ only intercluster exchange between triads (across the

2. M. V. Fedin, S. L. Veber, K. Yu. Maryunina, G. V. Romanenko, E. A. Suturina, N. P. Gritsan, R. Z. Sagdeev, V. I. Ovcharenko, E. G. Bagryanskaya. Intercluster Exchange Pathways in Polymer-Chain Molecular Magnets $\mathrm{Cu}(\mathrm{hfac})_{2} \mathrm{~L}^{\mathrm{R}}$ Unveiled by Electron Paramagnetic Resonance. J. Amer. Chem. Soc., 2010, 132, 13886-13891. 
chain) is remained. Interestingly, the position of $g_{\perp}$ signals of one-spin copper(II) ion also experiences shift upon each step of the $\chi \mathrm{T}(T)$ dependence, once again implying the corresponding changes of intercluster exchange. Last but not least, the EPR spectra at Q/W-bands can be fairly simulated (with deviations assigned to partial exchange narrowing). However, it turns out to be that integral intensity of spin triads is $\sim 0.3-0.5$ of the intensity of one-spin copper(II) ions (instead of theoretical 1). This is once again assigned to a rather strong intercluster exchange coupling between spin triads at $T<56 \mathrm{~K}$, being in qualitative agreement with noticeable decrease of $\chi \mathrm{T}(T)$ below 56 K.

\section{Figure S3.}

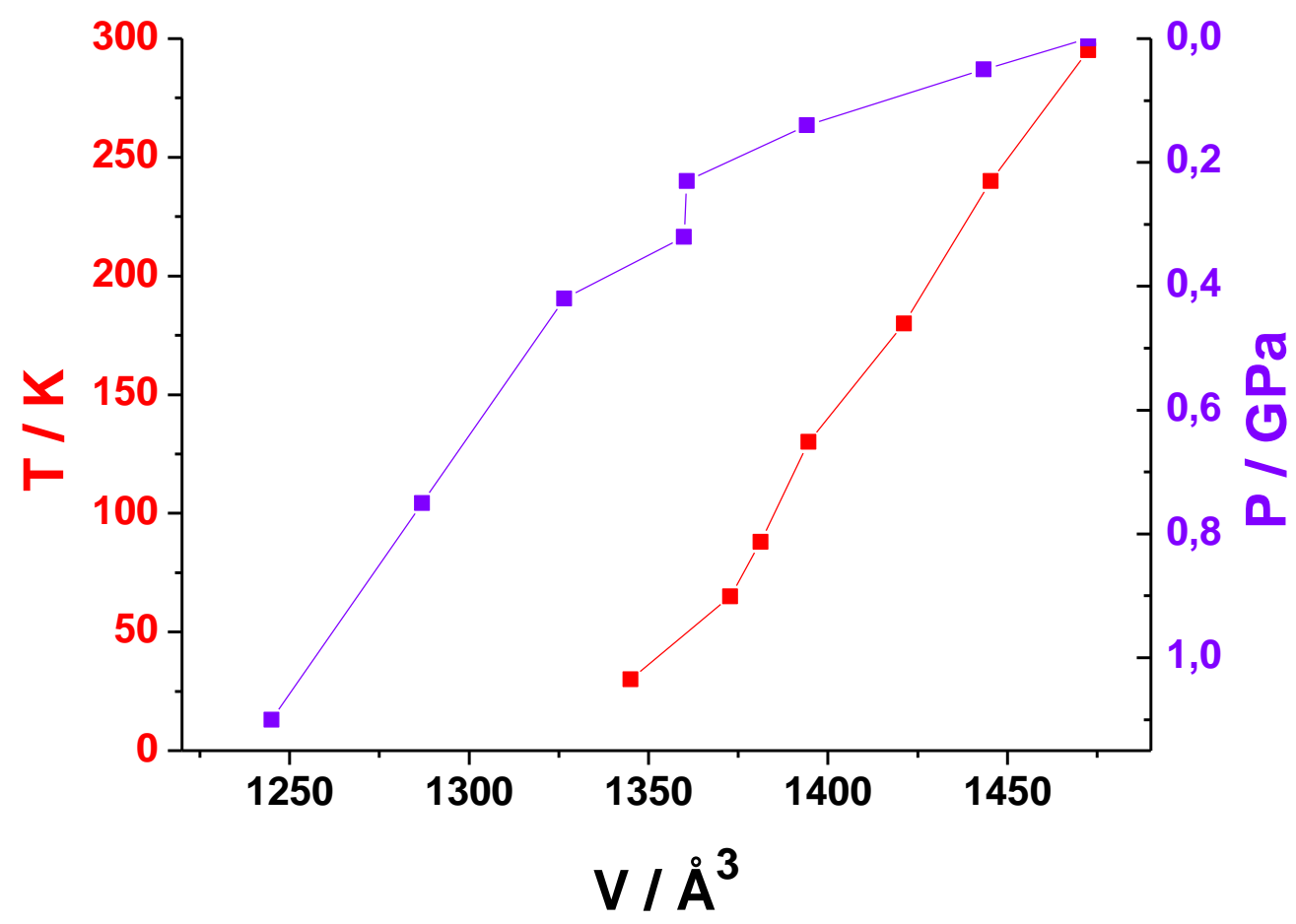

Figure S3. Variation of the unit cell volume V $\left(\AA^{3}\right)$ with temperature $(\square)$ and pressure $(\square)$. 


\section{Figure S4.}

$$
\begin{aligned}
& T=295 \mathrm{~K} \\
& P=0.0001 \mathrm{GPa} \\
& \mathrm{d}(-\mathrm{O} \ldots \mathrm{O}-\mathrm{O})=3.902 \AA \\
& V_{V}=80.2 \AA^{3}
\end{aligned}
$$

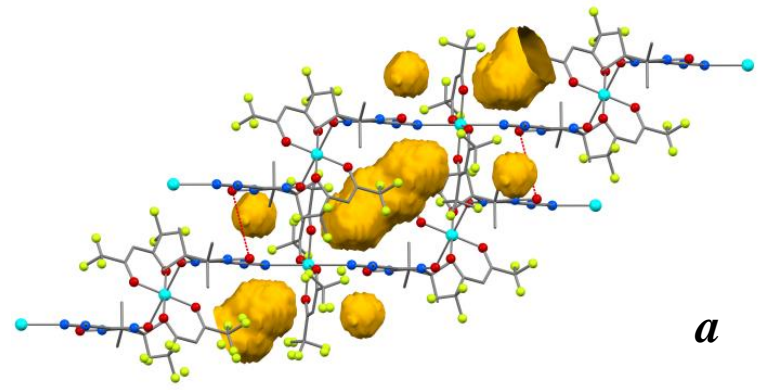

$130 \mathrm{~K}$

$0.0001 \mathrm{GPa}$ $3.657 \AA$ $55.1 \AA^{3}$
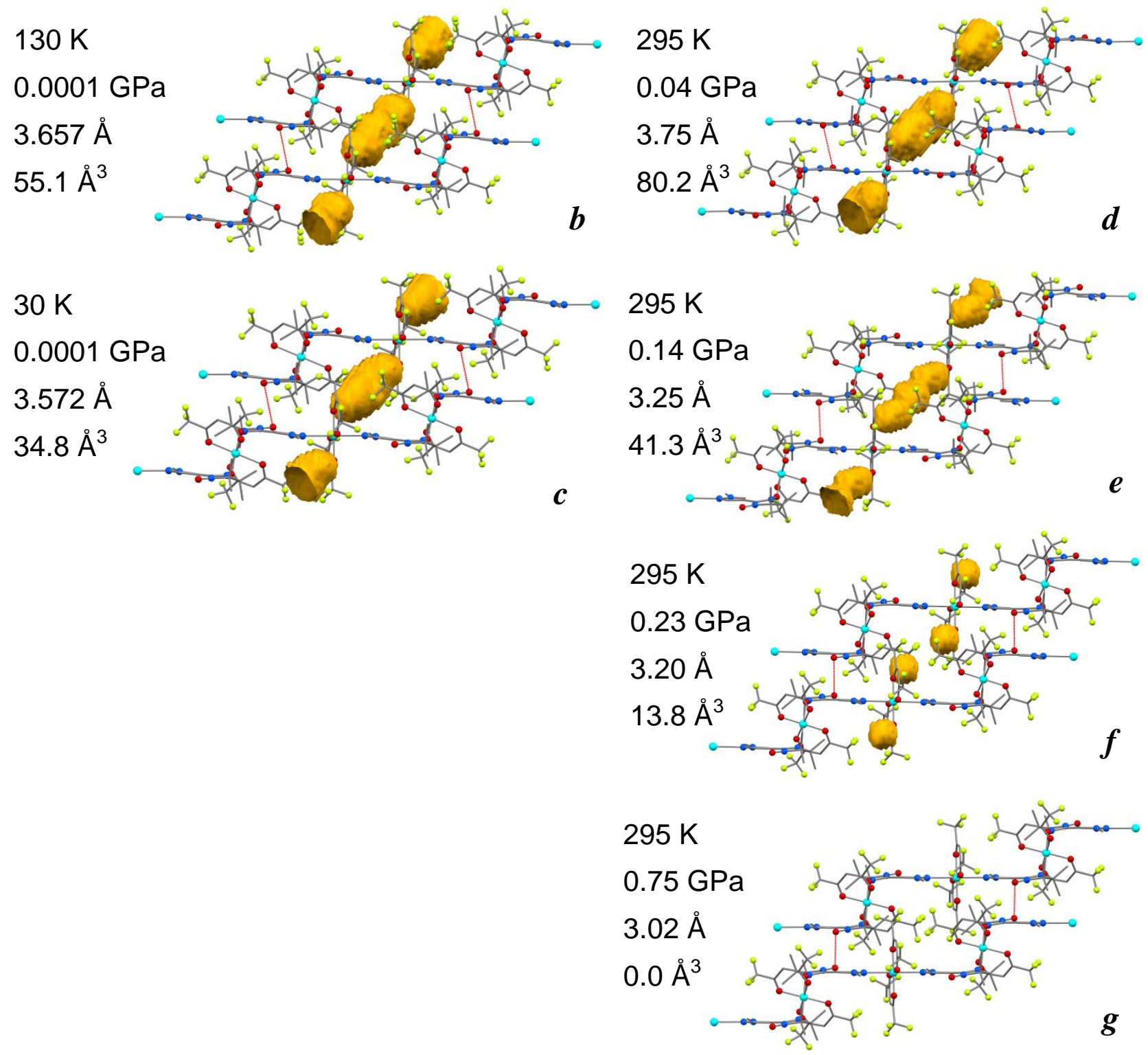

Figure S4. Transformations of interchain voids in $\left[\mathrm{Cu}(\mathrm{hfac})_{2} \mathrm{~L}\right]-\mathrm{II}$ with temperature $(a-c)$ and pressure $(a, d-g)$. The interchain O...O contacts are marked with a red line. The data $\mathrm{T}(\mathrm{K}), \mathrm{P}(\mathrm{GPa})$, the lengths of interchain contacts $d(\mathrm{O} \ldots \mathrm{O})(\AA)$ and the volume of voids $\mathrm{V}_{\mathrm{V}}\left(\AA^{3}\right.$, see also Tables $\mathrm{S} 1$ and S2) are given. 


\section{Figure S5.}

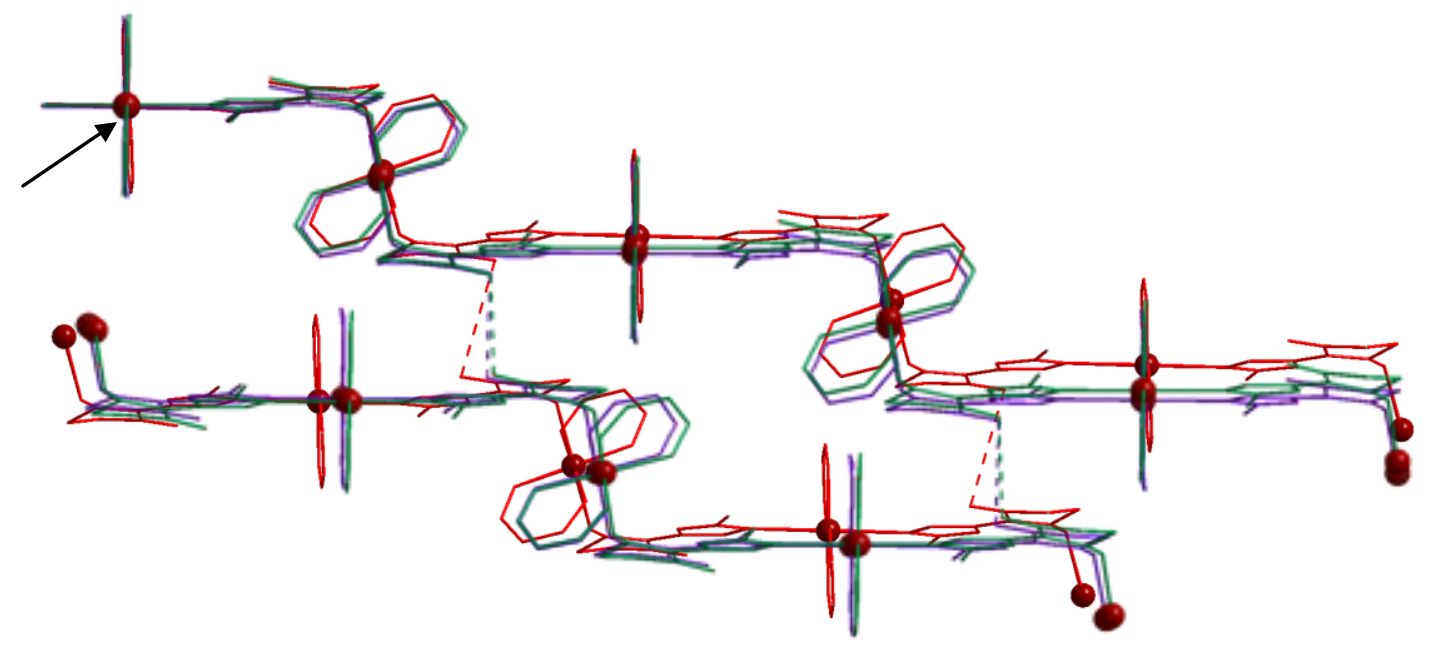

(a)

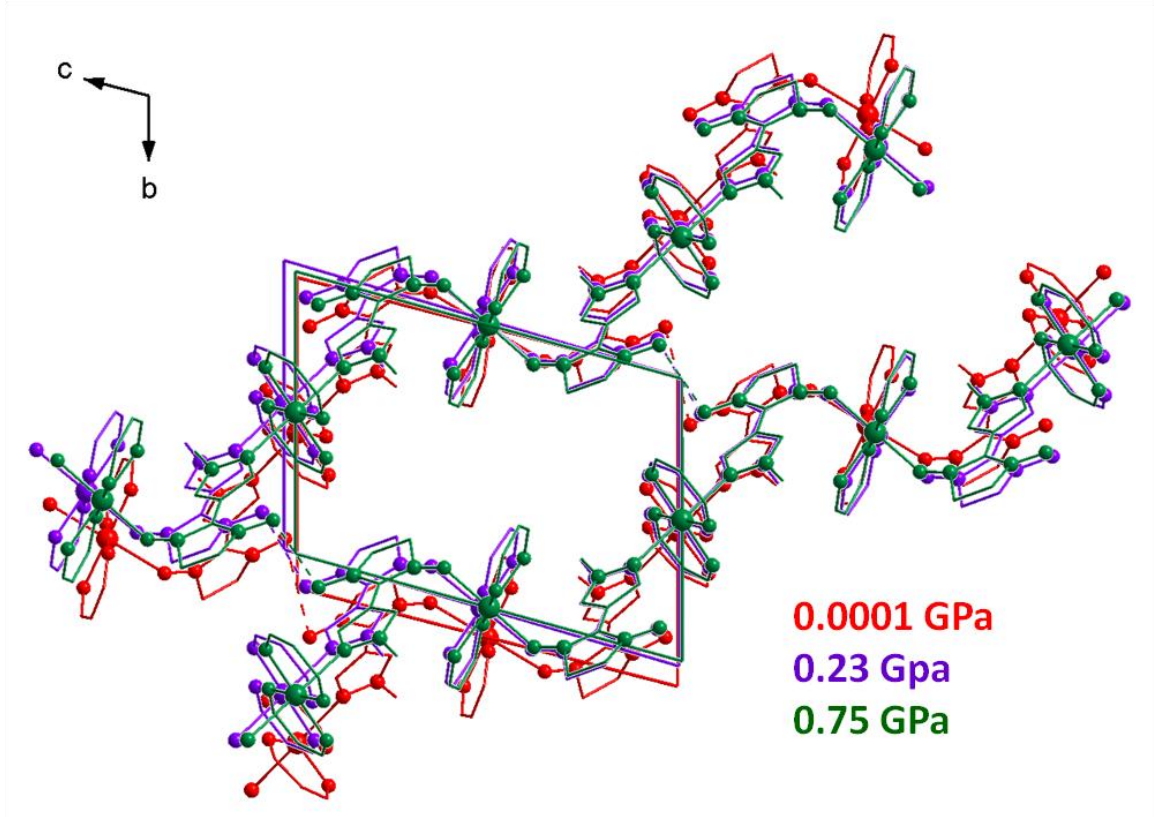

(b)

Figure S5. Visualization of structural changes in solid $\left[\mathrm{Cu}(\mathrm{hfac})_{2} \mathrm{~L}\right]-\mathrm{II}$ : (a) the extreme left $\mathrm{Cu}$ atom was fixed in the upper chain; (b) the origin of coordinates was fixed in the upper right corner of the cell. An increase in pressure to $0.23 \mathrm{GPa}$ leads not only to rotation of the chain axis, but also to a shift of polymer chains relative to one another and their approach. 


\section{Table S1.}

Table S1. Temperature variation of the selected bond lengths ( $\AA$ ), bond angles (deg.) and the volume of voids $\left(\mathrm{V}_{\mathrm{V}}, \AA^{3} / \%\right.$ of unit cell volume) in $\left[\mathrm{Cu}(\mathrm{hfac})_{2} \mathrm{~L}\right]-\mathrm{II}$ at ambient pessure.

\begin{tabular}{|c|c|c|c|c|c|c|c|c|c|}
\hline $\begin{array}{c}\mathrm{T}, \mathrm{K} \\
(\mathrm{P}= \\
0.0001 \\
\mathrm{GPa})\end{array}$ & $\mathrm{Cu}-\mathrm{O}_{\mathrm{NO}}$ & $\mathrm{Cu}-\mathrm{N}$ & $\mathrm{N}-\mathrm{O}_{\mathrm{Cu}}$ & $\mathrm{N}-\mathrm{O}$ & $\mathrm{Cu}-\mathrm{O}-\mathrm{N}$ & $-\mathrm{O} \ldots \mathrm{O}-$ & $\mathrm{N}^{\mathrm{Cu}}$ & $\mathrm{N}-\mathrm{O}$ & $\mathrm{V}_{\mathrm{V}}$ \\
\hline 295 & $2.336(1)$ & $2.557(2)$ & $1.288(2)$ & $1.272(2)$ & $131.8(1)$ & $3.902(3)$ & $1.288(2)$ & $1.272(2)$ & $80.2 / 5.4$ \\
\hline 240 & $2.319(1)$ & $2.522(1)$ & $1.293(2)$ & $1.274(2)$ & $130.7(1)$ & $3.803(2)$ & $1.293(2)$ & $1.274(2)$ & $39.7 / 2.8$ \\
\hline 180 & $2.298(2)$ & $2.495(2)$ & $1.292(2)$ & $1.277(2)$ & $129.9(1)$ & $3.722(2)$ & $1.292(2)$ & $1.277(2)$ & $37.3 / 2.6$ \\
\hline 130 & $2.181(2)$ & $2.476(2)$ & $1.300(2)$ & $1.280(2)$ & $128.2(1)$ & $3.657(2)$ & $1.300(2)$ & $1.280(2)$ & $55.1 / 4.0$ \\
\hline 88 & $2.150(2)$ & $2.461(2)$ & $1.300(3)$ & $1.280(2)$ & $127.8(1)$ & $3.617(3)$ & $1.300(3)$ & $1.280(2)$ & $27.6 / 2.0$ \\
\hline 65 & $2.107(2)$ & $2.458(2)$ & $1.306(3)$ & $1.279(3)$ & $127.9(2)$ & $3.601(3)$ & $1.306(3)$ & $1.279(3)$ & $33.1 / 2.4$ \\
\hline 30 & $2.000(2)$ & $2.456(3)$ & $1.302(3)$ & $1.265(3)$ & $126.9(2)$ & $3.572(3)$ & $1.302(3)$ & $1.265(3)$ & $34.8 / 2.6$ \\
\hline
\end{tabular}

\section{Table S2.}

Table S2. Pressure variation of the selected bond lengths $(\AA)$ bond angles (deg.) and the volume of voids $\left(\mathrm{V}_{\mathrm{V}}, \AA^{3} / \%\right.$ of unit cell volume) in $\left[\mathrm{Cu}(\mathrm{hfac})_{2} \mathrm{~L}\right]-\mathrm{II}$ at room temperature.

\begin{tabular}{|c|c|c|c|c|c|c|c|}
\hline $\begin{array}{c}\mathrm{P}, \mathrm{GPa} \\
(\mathrm{T}=295 \mathrm{~K})\end{array}$ & $\mathrm{Cu}-\mathrm{O}_{\mathrm{NO}}$ & $\mathrm{Cu}-\mathrm{N}$ & $\mathrm{N}-\mathrm{O}_{\mathrm{Cu}}$ & $\mathrm{N}-\mathrm{O}$ & $\mathrm{Cu}-\mathrm{O}-\mathrm{N}$ & $-\mathrm{O} \ldots \mathrm{O}-$ & $\mathrm{V}_{\mathrm{V}}$ \\
\hline 0.0001 & $2.336(1)$ & $2.557(2)$ & $1.289(2)$ & $1.273(2)$ & $131.9(1)$ & $3.902(3)$ & $80.2 / 5.4$ \\
\hline $0.02(5)$ & $2.308(10)$ & $2.548(6)$ & $1.288(8)$ & $1.282(6)$ & $132.6(7)$ & $3.89(1)$ & $75.0 / 5.1$ \\
\hline $0.04(5)$ & $2.294(8)$ & $2.545(4)$ & $1.296(6)$ & $1.279(5)$ & $131.9(6)$ & $3.75(1)$ & $66.8 / 4.6$ \\
\hline $0.14(5)$ & $2.275(9)$ & $2.516(6)$ & $1.290(7)$ & $1.278(6)$ & $130.4(7)$ & $3.25(1)$ & $41.3 / 3.0$ \\
\hline $0.23(5)$ & $2.234(11)$ & $2.561(8)$ & $1.342(17)$ & $1.350(16)$ & $129.2(11)$ & $3.20(2)$ & $13.8 / 1.0$ \\
\hline $0.32(5)$ & $2.202(12)$ & $2.539(8)$ & $1.335(18)$ & $1.336(18)$ & $127.8(12)$ & $3.16(2)$ & $12.1 / 0.9$ \\
\hline $0.42(5)$ & $2.167(13)$ & $2.539(9)$ & $1.304(18)$ & $1.261(14)$ & $129.0(12)$ & $3.13(2)$ & $14.9 / 1.1$ \\
\hline $0.75(5)$ & $2.052(12)$ & $2.481(9)$ & $1.298(18)$ & $1.262(14)$ & $126.3(12)$ & $3.02(2)$ & $0.0 / 0$ \\
\hline $1.09(5)$ & $2.013(8)$ & $2.439(5)$ & $1.304(6)$ & $1.269(5)$ & $124.9(6)$ & $2.95(1)$ & $0.0 / 0$ \\
\hline
\end{tabular}




\section{Table S3.}

Table S3. Quantum-chemical values of exchange interaction parameters $J$ and $J^{\prime}\left(\mathrm{cm}^{-1}\right)$ and theoretical values $\chi \mathrm{T}$, obtained using a static approach at different temperatures and atmospheric pressure. The values of g-factors of $\mathrm{Cu}(\mathrm{II})$ and radicals were taken 2.15 and 2.007 , respectively. ${ }^{3}$

\begin{tabular}{|c|c|c|c|c|c|c|c|c|c|}
\hline \multicolumn{10}{|c|}{$P=0.0001 \mathrm{GPa}$} \\
\hline \multicolumn{3}{|l|}{$T, \mathrm{~K}$} & 30 & 65 & 88 & 130 & 180 & 240 & 295 \\
\hline \multicolumn{3}{|c|}{$d\left(\mathrm{Cu}-\mathrm{O}_{\mathrm{NO}}\right), \AA$} & 2.000 & 2.107 & 2.150 & 2.181 & 2.298 & 2.319 & 2.336 \\
\hline \multicolumn{3}{|c|}{$d\left(\mathrm{Cu}-\mathrm{O}_{\mathrm{hfac}}\right), \AA$} & 2.303 & 2.200 & 2.155 & 2.114 & 1.998 & 1.978 & 1.966 \\
\hline \multicolumn{3}{|c|}{$d\left(\mathrm{O}_{\mathrm{NO}} \ldots \mathrm{O}_{\mathrm{NO}}\right), \AA$} & 3.572 & 3.601 & 3.617 & 3.657 & 3.722 & 3.803 & 3.902 \\
\hline \multicolumn{3}{|c|}{$\omega$} & 1.00 & 0.69 & 0.56 & 0.45 & 0.10 & 0.04 & 0.00 \\
\hline \multicolumn{10}{|c|}{ Intracluster magnetic couplings, $\mathrm{cm}^{-1}$} \\
\hline \multirow{2}{*}{\multicolumn{2}{|c|}{ UB3LYP/TZVP }} & $J \mathrm{O}-\mathrm{Cu}-$ & -682 & -409 & -262 & -143 & 37 & 37 & 37 \\
\hline & & $J^{\prime} \mathrm{O} \ldots(\mathrm{Cu}) \ldots \mathrm{O}$ & -17 & 18 & 24 & 20 & -4 & -4 & -4 \\
\hline \multicolumn{2}{|c|}{ UB3LYP/def2-TZVP* } & $J \mathrm{O}-\mathrm{Cu}-$ & -665 & -383 & -236 & -119 & 38 & 38 & 17 \\
\hline \multicolumn{2}{|c|}{ GGA+U* } & $J \mathrm{O}-\mathrm{Cu}-$ & -589 & -294 & -178 & -92 & 26 & 27 & 27 \\
\hline \multicolumn{10}{|c|}{ Interchain magnetic coupling $J^{0 \ldots \mathrm{O}}, \mathrm{cm}^{-1}$} \\
\hline \multicolumn{3}{|c|}{ UB3LYP/TZVP } & -25 & -23 & -22 & -21 & -20 & -17 & -14 \\
\hline \multicolumn{3}{|c|}{ UB3LYP/def2-TZVP } & -19 & -17 & -17 & -17 & -17 & -14 & -18 \\
\hline \multicolumn{3}{|c|}{ GGA+U } & -26 & -5 & -9 & -15 & -32 & -29 & -24 \\
\hline \multicolumn{10}{|c|}{$\chi \mathrm{T}, \mathrm{cm}^{3} \cdot \mathrm{K} \cdot \mathrm{mol}^{-1}$} \\
\hline \multicolumn{3}{|l|}{$\chi \mathrm{T}$ exp. } & 0.36 & 0.57 & 0.66 & 0.70 & 0.86 & 0.88 & 0.90 \\
\hline \multirow{3}{*}{$\chi \mathrm{T}$ calc. } & \multicolumn{2}{|c|}{ UB3LYP/TZVP** } & \begin{tabular}{|l|}
0.40 \\
$(0.32)$ \\
\end{tabular} & $\begin{array}{l}0.59 \\
(0.52) \\
\end{array}$ & \begin{tabular}{|l|}
0.66 \\
$(0.60)$ \\
\end{tabular} & \begin{tabular}{|l|}
.70 \\
$(0.66)$ \\
\end{tabular} & \begin{tabular}{|l|}
0.86 \\
$(0.83)$ \\
\end{tabular} & \begin{tabular}{|l|l}
0.87 \\
$(0.85)$ \\
\end{tabular} & \begin{tabular}{|l|}
0.88 \\
$(0.86)$ \\
\end{tabular} \\
\hline & \multicolumn{2}{|c|}{ UB3LYP/def2-TZVP** } & \begin{tabular}{|l|}
.40 \\
$(0.33)$ \\
\end{tabular} & $\begin{array}{l}0.57 \\
(0.50) \\
\end{array}$ & $\begin{array}{l}0.62 \\
(0.57) \\
\end{array}$ & \begin{tabular}{|l|}
0.66 \\
$(0.63)$ \\
\end{tabular} & \begin{tabular}{|l|}
0.82 \\
$(0.79)$ \\
\end{tabular} & $\begin{array}{l}0.83 \\
(0.81) \\
\end{array}$ & \begin{tabular}{|l|}
0.84 \\
$(0.83)$ \\
\end{tabular} \\
\hline & \multicolumn{2}{|c|}{ GGA+U** } & \begin{tabular}{|l|}
.40 \\
$(0.32)$ \\
\end{tabular} & $\begin{array}{l}0.58 \\
(0.49) \\
\end{array}$ & $\begin{array}{l}0.64 \\
(0.57) \\
\end{array}$ & \begin{tabular}{|l|}
0.68 \\
$(0.63)$ \\
\end{tabular} & \begin{tabular}{|l|}
0.84 \\
$(0.80)$ \\
\end{tabular} & $\begin{array}{l}0.85 \\
(0.82) \\
\end{array}$ & \begin{tabular}{|l|}
0.86 \\
$(0.84)$ \\
\end{tabular} \\
\hline
\end{tabular}

* The calculation of $J$ ' by these methods was not made.

** The values of $\mathrm{Cu}-\mathrm{O}$ bond lengths for exchange clusters at atmospheric pressure $(\mathrm{T}=295$ and 30 $\mathrm{K})$ were taken as the reference values, when under experimental conditions the maximum accumulation in the solid phase was weak $(\omega=0)$ and strongly bound $(\omega=1)$ triads, respectively. Values in parentheses are the results of calculation taking into account interchain exchange.

3. Zueva, E. M.; Ryabykh, E. R.; Kuznetsov, An. M. Microscopic mechanisms of magnetic transitions in chain polymeric copper(II) complexes with nitronyl nitroxide radicals. Russ. Chem. Bull., 2009, 58, 16541662 . 


\section{Table S4.}

Table S4. Quantum-chemical values of exchange interaction parameters $J$ and $J^{\prime}\left(\mathrm{cm}^{-1}\right)$ and theoretical values $\chi \mathrm{T}$, obtained using a static approach at room temperature and different pressures. The values of $\mathrm{Cu}$ (II) g-factors and radicals were taken 2.15 and 2.007 , respectively. ${ }^{3}$.

\begin{tabular}{|c|c|c|c|c|c|c|c|}
\hline \multicolumn{8}{|c|}{$T=295 \mathrm{~K}$} \\
\hline \multicolumn{3}{|l|}{$P, \mathrm{GPa}$} & 0.0001 & 0.23 & 0.30 & 0.42 & 0.75 \\
\hline \multicolumn{3}{|c|}{$d\left(\mathrm{Cu}-\mathrm{O}_{\mathrm{NO}}\right), \AA$} & 2.336 & 2.234 & 2.202 & 2.167 & 2.052 \\
\hline \multicolumn{3}{|c|}{$d\left(\mathrm{Cu}-\mathrm{O}_{\mathrm{hfac}}\right), \AA$} & 1.966 & 1.971 & 1.969 & 2.022 & 2.125 \\
\hline \multicolumn{3}{|c|}{$d\left(\mathrm{O}_{\mathrm{NO}} \ldots \mathrm{O}_{\mathrm{NO}}\right), \AA$} & 3.902 & 3.20 & 3.16 & 3.13 & 3.02 \\
\hline \multicolumn{3}{|c|}{$\omega$} & 0.0 & 0.16 & 0.21 & 0.33 & 0.65 \\
\hline \multicolumn{8}{|c|}{ Intracluster magnetic couplings $J, \mathrm{~cm}^{-1}$} \\
\hline \multirow{2}{*}{\multicolumn{2}{|c|}{ UB3LYP/TZVP }} & $J \mathrm{O}-\mathrm{Cu}-$ & 37 & 45 & 44 & 42 & -493 \\
\hline & & $J^{\prime} \mathrm{O} \ldots(\mathrm{Cu}) \ldots \mathrm{O}$ & -4 & -6 & -5 & 1 & 50 \\
\hline \multirow{2}{*}{\multicolumn{2}{|c|}{$\begin{array}{l}\text { UB3LYP/def2-TZVP* } \\
\text { GGA+U* }\end{array}$}} & $J \mathrm{O}-\mathrm{Cu}-$ & 17 & 22 & 51 & 50 & -458 \\
\hline & & $J \mathrm{O}-\mathrm{Cu}-$ & 27 & 33 & 32 & 20 & -318 \\
\hline \multirow{2}{*}{\multicolumn{3}{|c|}{ UB3LYP/TZVP }} & gnetic cr & $\operatorname{ling} J^{0 .}$ & & & \\
\hline & & & -14 & 8 & 7 & -5 & -22 \\
\hline \multicolumn{3}{|c|}{ UB3LYP/def2-TZVP } & -18 & 6 & 5 & -3 & -14 \\
\hline \multicolumn{3}{|c|}{ GGA+U } & -24 & -3 & -3 & 42 & 16 \\
\hline \multicolumn{8}{|c|}{$\chi \mathrm{T}, \mathrm{cm}^{3} \cdot \mathrm{K} \cdot \mathrm{mol}^{-1}$} \\
\hline \multirow{3}{*}{$\chi \mathrm{T}$ calc. } & \multicolumn{2}{|c|}{ UB3LYP/TZVP } & $\begin{array}{l}0.88 \\
(0.86)\end{array}$ & $\begin{array}{l}0.80 \\
(0.78)\end{array}$ & $\begin{array}{l}0.77 \\
(0.76)\end{array}$ & $\begin{array}{l}0.72 \\
(0.70)\end{array}$ & $\begin{array}{l}0.56 \\
(0.55)\end{array}$ \\
\hline & \multicolumn{2}{|c|}{ UB3LYP/def2-TZVP } & $\begin{array}{l}0.84 \\
(0.83)\end{array}$ & $\begin{array}{l}0.77 \\
(0.76)\end{array}$ & $\begin{array}{l}0.75 \\
(0.73)\end{array}$ & $\begin{array}{l}0.70 \\
(0.68)\end{array}$ & $\begin{array}{l}0.55 \\
(0.54)\end{array}$ \\
\hline & \multicolumn{2}{|l|}{$\mathrm{GGA}+\mathrm{U}$} & $\begin{array}{l}0.86 \\
(0.84)\end{array}$ & $\begin{array}{l}0.79 \\
(0.76)\end{array}$ & $\begin{array}{l}0.76 \\
(0.74)\end{array}$ & $\begin{array}{l}0.71 \\
(0.69)\end{array}$ & $\begin{array}{l}0.56 \\
(0.55)\end{array}$ \\
\hline
\end{tabular}

* The calculation of $J$ ' by these methods was not made.

** The values of $\mathrm{Cu}-\mathrm{O}$ bond lengths for exchange clusters at atmospheric pressure $(\mathrm{T}=295$ and 30 $\mathrm{K})$ were taken as the reference values, when under experimental conditions the maximum accumulation in the solid phase was weak $(\omega=0)$ and strongly bound $(\omega=1)$ triads, respectively. Values in parentheses are the results of calculation taking into account interchain exchange. 


\section{Interpretation of the anomalous behavior of $\chi \mathrm{T}(T)$ at low pressures}

The calculation of exchange integrals for the structure at $\mathrm{P}=0.04 \mathrm{GPa}(\mathrm{T}=295 \mathrm{~K})$ gave $J_{\text {intra }}$ $=28 \mathrm{~cm}^{-1}$ for the intracluster exchange integral and $J_{\text {chain }}=-26 \mathrm{~cm}^{-1}$ for the interchain one. The temperature dependence $\chi \mathrm{T}(T)$ for these parameters of the problem is represented by a dashed curve in Figure S6. The systematic deviations of the calculated curve from the experimental $\chi \mathrm{T}(T)$ dependence (blue dots) at high temperatures indicate that an impurity of low-spin exchange clusters with a large intracluster antiferromagnetic exchange integral $J_{\text {intra }}$ appears in the system even at low pressures. Evaluation of the fraction of this impurity at $\mathrm{P}=0.04 \mathrm{GPa}(\mathrm{T}=295 \mathrm{~K})$ gave $\omega_{\mathrm{LT}}=0.08$. At the same time, the position of the experimental $\chi \mathrm{T}(T)$ curve above the calculated black dashed curve at low tempratures suggests that the interchain exchange that is responsible for the lowtemperature decay of $\chi \mathrm{T}(T)$ is evidently smaller (in magnitude) than the above-given value of $J_{\text {chain }}=$ $-26 \mathrm{~cm}^{-1}$. Let us take $\chi \mathrm{T}(\mathrm{T})$ at $\mathrm{P}=0.75 \mathrm{GPa}$ as a reference function corresponding to the temperature dependence $\chi \mathrm{T}(\mathrm{LT})$ for the exchange clusters in the ground state (low-temperature exchange clusters). This $\chi \mathrm{T}(\mathrm{LT})$ function is well approximated by the exchange integrals $J_{\text {intra }}=-$ $170 \mathrm{~cm}^{-1}$ and $J_{\text {chain }}=-34 \mathrm{~cm}^{-1}$, which slightly differs from the calculated quantum-chemical values given in Table S4. Weighing the contributions of the low- and high-temperature exchange clusters by the equation used above, $(\chi \mathrm{T})^{2}=\omega_{L T}(\chi \mathrm{T})^{2}(\mathrm{LT})+\left(1-\omega_{L T}\right)(\chi \mathrm{T})^{2}(\mathrm{HT})$, we obtained a red curve in Figure S6, which satisfactorily describes the experiment over the whole temperature range. For the high-temperature values of exchange integrals, we used the fitting values of $J_{\text {intra }}=10 \mathrm{~cm}^{-1}$ and $J_{\text {chain }}$ $=-15 \mathrm{~cm}^{-1}$. These values qualitatively agree with the calculated values of $J_{\text {intra }}$ and $J_{\text {chain }}$ for $\mathrm{P}=10^{-4}$ $\mathrm{GPa}(\mathrm{T}=295 \mathrm{~K})$ listed in Table S4. The suggested reason for the effect lies in the fact that the $H T \leftrightarrow L T$ temperature transition is sterically hindered at low pressures for the exchange clusters because of the specific deformation of polymer chains, and the above formula is applicable at all temperatures with $\omega_{\mathrm{LT}}=$ const, in contrast to the case of atmospheric pressure $\mathrm{P}=10^{-4} \mathrm{GPa}$, when this coefficient changes in accordance with Table S3. 


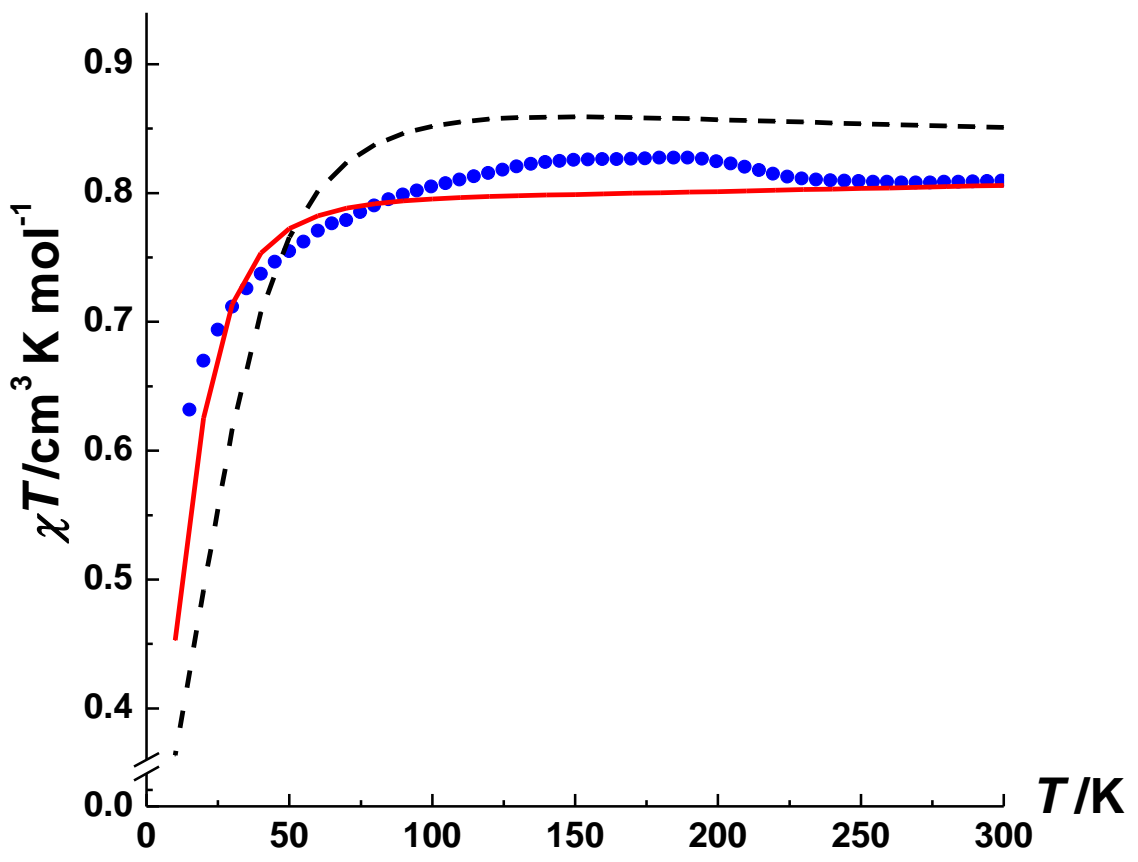

Figure S6. The blue dots are experimental data for $\mathrm{P}=0.07 \mathrm{GPa}$ (cooloing mode), the black dash line is the calculated curve using the exchange integrals found for the structure at $\mathrm{P}=0.04 \mathrm{GPa}$, the red curve is the weighted approximation. 


\section{Table S5}

Table S5. Temperature and compression dynamics of crystallographic parameters and experimental details for $\left[\mathrm{Cu}(\mathrm{hfac})_{2} \mathrm{~L}\right]-\mathrm{II}$.

\begin{tabular}{|c|c|c|c|c|c|c|c|c|}
\hline $\begin{array}{l}\mathrm{T}, \mathrm{K} \\
(\mathrm{P}=0.0001 \mathrm{GPa})\end{array}$ & 295 & 240 & 180 & 130 & 88 & 65 & 30 & \\
\hline$a, \AA$ & $11.1110(4)$ & $10.9906(2)$ & $10.8970(2)$ & $10.8467(3)$ & $10.8116(2)$ & $10.8010(4)$ & $10.729(2)$ & \\
\hline$b, \AA$ & $10.2364(4)$ & $10.2219(2)$ & $10.2039(2)$ & $10.2055(3)$ & $10.1954(3)$ & $10.1932(4)$ & $10.185(2)$ & \\
\hline$c, \AA$ & $13.7642(5)$ & $13.7030(3)$ & $13.6221(3)$ & $13.4202(3)$ & $13.3461(3)$ & $13.2747(5)$ & $13.064(3)$ & \\
\hline$\alpha,^{\circ}$ & $95.103(2)$ & $95.659(1)$ & $96.042(1)$ & $96.392(1)$ & $96.534(2)$ & $96.566(2)$ & $97.00(3)$ & \\
\hline$\beta, \circ$ & $102.939(2)$ & $103.012(1)$ & $102.980(1)$ & $102.638(1)$ & $102.512(1)$ & $102.394(2)$ & $102.32(3)$ & \\
\hline$\gamma,{ }^{\circ}$ & $102.702(2)$ & $102.688(1)$ & $102.619(1)$ & $102.629(1)$ & $102.630(2)$ & $102.639(2)$ & $101.82(3)$ & \\
\hline$V, \AA^{3}$ & $1472.61(11)$ & $1445.44(5)$ & $1421.22(5)$ & $1394.60(6)$ & $1381.23(6)$ & $1372.75(9)$ & $1344.6(5)$ & \\
\hline$D_{\text {calc }}, \mathrm{g} \cdot \mathrm{cm}^{-3}$ & 1.612 & 1.643 & 1.671 & 1.703 & 1.719 & 1.730 & 1.766 & \\
\hline$\theta_{\max }, \circ$ & 29.154 & 30.028 & 30.255 & 30.568 & 28.343 & 28.620 & 28.968 & \\
\hline $\begin{array}{l}I_{\mathrm{hkl}} \text { meas } / I_{\mathrm{hkl}} \text { uniq } \\
R_{\mathrm{int}}\end{array}$ & $\begin{array}{l}26590 / 7772 \\
0.0422\end{array}$ & $\begin{array}{l}26968 / 8290 \\
0.0310\end{array}$ & $\begin{array}{l}2847 / 8167 \\
0.0514\end{array}$ & $\begin{array}{l}26288 / 8378 \\
0.0399\end{array}$ & $\begin{array}{l}27962 / 6816 \\
0.0546\end{array}$ & $\begin{array}{l}23642 / 6854 \\
0.0587\end{array}$ & $\begin{array}{l}17306 / 6750 \\
0.0568\end{array}$ & \\
\hline $\mathrm{I}_{\mathrm{hkl}}>2 \sigma_{I} / N$ & $3821 / 535$ & $51626 / 508$ & $4708 / 427$ & $5278 / 427$ & $4582 / 418$ & 4133 / 427 & $4633 / 400$ & \\
\hline Goof & 0.803 & 0.936 & 0.859 & 0.961 & 0.991 & 0.928 & 0.993 & \\
\hline$R 1 / w R 2\left(I>2 \sigma_{I}\right)$ & $0.0356 / 0.0800$ & $0.0383 / 0.0939$ & $0.0422 / 0.1005$ & $0.0392 / 0.0924$ & $0.0392 / 0.0901$ & $0.0449 / 0.0941$ & $0.0453 / 0.1127$ & \\
\hline $\begin{array}{l}\mathrm{P}, \mathrm{GPa} \\
(\mathrm{T}=295 \mathrm{~K})\end{array}$ & $0.02(5)$ & $0.04(5)$ & $0.14(5)$ & $0.23(5)$ & $0.32(5)$ & $0.42(5)$ & $0.75(5)$ & $1.10(5)$ \\
\hline$a, \AA$ & $11.0895(4)$ & $10.9524(4)$ & $10.2682(4)$ & $10.1175(8)$ & $10.1156(9)$ & $9.9914(6)$ & $9.8800(11)$ & $9.7664(4)$ \\
\hline$b, \AA$ & $10.2358(2)$ & $10.2271(2)$ & $10.1791(2)$ & $10.1263(15)$ & $10.1244(18)$ & $10.0827(11)$ & $10.019(2)$ & $9.9217(2)$ \\
\hline$c, \AA$ & $13.7487(4)$ & $13.7161(4)$ & $14.2921(4)$ & $14.2272(18$ & $14.2246(19)$ & $14.0907(12)$ & $13.885(3)$ & $13.7566(4)$ \\
\hline$\alpha,^{\circ}$ & $95.2030(10)$ & $95.6350(10)$ & $96.805(2)$ & $97.061(10)$ & $97.052(11)$ & $97.279(7)$ & $97.597(14)$ & $97.9750(10)$ \\
\hline$\beta,{ }^{\circ}$ & $102.939(2)$ & $103.098(2)$ & $104.771(2)$ & $104.597(8)$ & 104.617(9) & $104.253(6)$ & $103.650(11)$ & $103.159(2)$ \\
\hline$\gamma, \circ$ & $102.682(2)$ & $102.487(2)$ & $101.291(2)$ & $101.225(10)$ & $101.209(12)$ & $101.221(7)$ & $101.252(14)$ & $101.282(2)$ \\
\hline$V, \AA^{3}$ & $1467.74(8)$ & $1443.38(7)$ & 1393.98(7) & $1360.7(3)$ & $1359.9(3)$ & $1326.5(2)$ & $1286.9(4)$ & $1249.25(7)$ \\
\hline$D_{\text {calc }}, \mathrm{g} \cdot \mathrm{cm}^{-3}$ & 1.618 & 1.645 & 1.703 & 1.745 & 1.746 & 1.790 & 1.845 & 1.901 \\
\hline$\theta_{\max }$, & 28.172 & 28.085 & 28.223 & 26.389 & 24.968 & 24.770 & 24.779 & 28.747 \\
\hline $\begin{array}{l}I_{\mathrm{hkl}} \text { meas } / I_{\mathrm{hkl}} \text { uniq } \\
R_{\mathrm{int}}\end{array}$ & $\begin{array}{l}11077 / 2171 \\
0.0509\end{array}$ & $\begin{array}{l}10864 / 2143 \\
0.0513\end{array}$ & $\begin{array}{l}10614 / 2090 \\
0.0275\end{array}$ & $\begin{array}{l}8226 / 1815 \\
0.2477\end{array}$ & $\begin{array}{l}6914 / 1610 \\
0.2494\end{array}$ & $\begin{array}{l}8032 / 1653 \\
0.1069\end{array}$ & $\begin{array}{l}7070 / 1583 \\
0.2546\end{array}$ & $\begin{array}{l}9522 / 1860 \\
0.0252\end{array}$ \\
\hline$I_{h k l}>2 \sigma_{I} / N$ & $1525 / 372$ & $1542 / 393$ & $1623 / 401$ & $734 / 393$ & $732 / 393$ & $832 / 393$ & $761 / 393$ & $1594 / 401$ \\
\hline Goof & 0.963 & 1.060 & 1.037 & 1.033 & 1.012 & 1.104 & 1.092 & 1.101 \\
\hline$R 1 / w R 2\left(I>2 \sigma_{I}\right)$ & $0.0476 / 0.1247$ & $0.0493 / 0.1391$ & $0.0480 / 0.1209$ & $0.0787 / 0.1642$ & $0.0785 / 0.1833$ & $0.0886 / 0.2249$ & $0.0764 / 0.2006$ & $0.0384 / 0.1074$ \\
\hline
\end{tabular}


